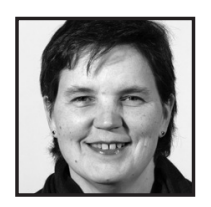

\title{
Linking Education to Community in the Context of Learning by Designing Solutions for an Ever-Growing Humanitarian Crisis
}

Tiiu Poldma, Université de Montréal

\section{ABSTRACT}

This paper explores how students in a Quebec university encounter world humanitarian crises within the context of a refugee camp in Jordan, explored from the perspective of co-creation within a design class workshop.' Students ${ }^{2}$ create solutions together in groups, using a project-based approach that incorporates collaborative learning and integrate aesthetic thinking with ethical and sustainable proposals that consider humanity within camps. They develop potentially usable solutions that are then presented to experts in the humanitarian community. The workshop goals, learning activities, and results are presented with three examples of student projects. In this type of learning environment, project-based approaches frame co-creation and collaborative learning.

\section{Designing in Context: Considering a Humanitarian Design Approach}

s of summer 2016, the United Nations reports that the world refugee
crisis has hit an all-time high with 65.3 million refugees worldwide,
with Syrian refugees accounting for over 6 million worldwide (UN Refugee Agency, 2016). The ravages of war and world strife lead to the displacement of many seeking asylum (UN Refugee Agency, 2014; UNICEF, 2015; Edwards, 2016), crises that include economic unrest and political unrest, and with consequences that affect people being displaced for increasingly longer periods of time. Temporary refugee 
camps have become permanent homes in several countries such as Jordan, Iran, and Lebanon (UN Refugee Agency, 2016), with people living essentially in tents, regardless of weather and living conditions. There are entire families at risk and, in particular, children, who account for an increasing percentage of refugees, often as orphans living with haunting personal traumas. Severe winter conditions add to the difficulties, and families are in need more than ever before (UNICEF, 2015).

With these issues in mind, transformative, creative, and innovative solutions can be sought out to alleviate these dire and difficult living situations, by creating environments that allow refugees to live in humane conditions where they can do more than merely survive. Designing in general, and designing interiors specifically, may be considered to be frivolous when considered from the more traditional aesthetic contexts alone. Conversely, designing can be put to use as proactive when the contexts of how people actually live are understood. A humanitarian design approach provides men, women, and children opportunities when the designing integrates creative and aesthetic ideas both sensitive to local cultural contexts and that use practical and technically appropriate design solutions to solve serious problems. Humanitarian design can afford possibilities and practical solutions for daily living issues and provide hope for those who are suffering.

Two professors came together to develop a design workshop in a studio within a baccalaureate program, to provide students with a co-creation learning exercise to consider solutions for these types of questions. The design workshop would both challenge students and their concepts about people who live as refugees, and also would provide students with new ways of thinking, to develop creative solutions for these very difficult problems. As one professor, Claude, suggests, in this workshop proposal, "Design can (and should) provide a way out-be responsible and human, by integrating ecological, social ethical, and political responses using design tools as the catalyst for solutions that are ecological, ethical, and economically and locally viable."

Humanitarian design is not only at the service of urgent needs of men, women, and children, all survivors living in critically unsafe spaces, but also carries a responsibility to afford solutions in ways that transcend the living situations of those in need by offering alternatives and possibilities that allow their lives to move beyond mere survival within their actual, lived situation. Humanitarian design offers innovative solutions by inventing new alternatives that can be applied as agents of change, meaning that design concepts can help people envision how to transform existing realities and situations into better ones that improve their situation. 


\section{Linking Learning With Community and Society in the Context of a Humanitarian Workshop}

In disciplines such as interior design and architecture, learning experiences focus on individually created visual concepts and solutions that are often beautiful and usually functional. However, these solutions are not always created with broader world issues in mind. Linking learning with the larger issues of community and society are essential experiences for students to acquire in their journey to become ethical professionals that solve problems in society.

The workshop was developed from the perspectives of an interior design professor in Montreal and an architect/professor from Paris with firsthand experiences in the Syrian refugee camps in Jordan. We came together to develop learning activities that use co-creation designing strategies, to provide students with experiences where they would develop solutions for the humanitarian crisis in the Middle East. As we discussed creating the workshop learning activities, we were concerned about past individual experiences as teachers witnessing beautiful design being created in design studio classes, yet usually not considering the experiences of people in difficult situations or of designs created in context. The co-creation approach we developed provides a place for students to examine the difficult issues of refugees in camps together and create potential solutions using collaborative and conversational techniques. While we knew that in the Winter of 2014 the refugee crisis was not a real and tangible event in our students lives, we wanted to help them to hone their design skills by learning how to solve problems for crisis situations, make them aware of this serious crisis and how their design skills might make a difference.

The learning activity presented here is a design workshop that was done in a baccalaureate design theory course in Quebec, where students explored the situation of people living in a Syrian refugee camp in Jordan from the perspective of the living conditions considered to be "home" for millions. Refugee camps such as Zaatari in Jordan are becoming even more ill equipped for the realities of everyday living. Living conditions are such that, while meant to be temporary, the accommodations often become a permanent home to thousands, indeed millions of men, women, and children, who live under duress and in critical situations. How people live, indeed survive in these conditions, becomes a design situation in that designing potential concepts and solutions can at least offer hope for those in need. Currently, finding solutions for these types of crises are not usually associated with design problem solving. In fact, the camps at that time were ill equipped to deal with the increased influx of people, and even less so to deal with how to house them adequately (Yacoub, 2014). 
We present what happens when two seemingly divergent concepts come together: examining potential design solutions for a humanitarian crisis, and doing so using design learning from theoretical perspectives of light, color, and form learned and then applied into proposed solutions. In this type of learning environment, project-based approaches frame co-design, defined as co-creation in a collaborative learning context. Students are asked to consider issues of ethics and sustainability from the perspectives of project-based learning, and to do so together as they co-create concepts for the given contexts. They are asked to consider humanitarian, social, cultural, theoretical, or practical contexts from multiple perspectives. They then apply these considerations in the creation of design concepts. This humanitarian design approach brings theory and practice together, as both students and teachers consider reflective perspectives from critical standpoints and as students then apply problem-solving skills by designing informed concepts.

Three project examples show how students delve into the issues and propose concept solutions. Students uncover meanings through both conversation and in the design concepts that are developed, as they grapple with uncovering the voices of refugees and responding to their needs with creative, useful, and sustainable solutions. Within 35 different groups in two classes, students produced dynamic and thoughtful solutions. Linking back into the community happened both in the form of engaging jury members who critiqued the work and who were familiar with the humanitarian issues firsthand, presenting the ideas at a major humanitarian conference, and in the individual efforts of the newly engaged students in initiatives since the workshop occurred. The most relevant concepts were presented to the worldwide humanitarian aid community at a major international conference on humanitarian design and the Syrian crisis in Montreal, Canada in April 2014. The best solutions were presented and considerations made for their potential use in the future. The discussion and conclusion suggest how the classroom experiences inform students immediately in the workshop experience as well as decision-makers later on in the refugee community, providing design solutions as potential agents of change.

\section{Issues Within the Context of Design Learning: About Thinking and Doing}

Design professor and architect John Weigand (in Senge et al., 2000) identifies some of the core elements of design learning. He proposes that design learning is a different type of learning from the conventional classroom, with hands on, project-based design scenarios as a fundamental element of good design learning. It is necessary for students to understand complex issues, where design problem-solving and solution-finding is required and/or desired 
(Poldma, 2009, pp. 6-7). Weigand speaks to the dynamics of design as "problemposing" and how motivating the student is an essential part of design teaching and learning. As he states, rather than focusing on "...the conventional extrinsic motivators, such as professor's course syllabus and grades....they were more invested in what they were doing rather than how they were doing" (Weigand in Senge, 2000 , p. 179). Students need to understand the issues, develop empathy for the user, and experience the conditions that can then bring about design ideas. (Vaikla Poldma, 2003; Poldma, 2009). Weigand proposes that design learning requires teachers to vision with students. He states:

Our students want to become architects and interior designers. If I want to tap into those visions, I need to invite them to participate in the process that gets them there, not as receivers but as active participants.... have begun asking some of the same questions... 'To reach your desired future, what do you need to know?' (Weigand in Senge, 2000, p. 179)

As design teachers collaborating together, we were asking these same questions and wanting these experiences for our students. While we both considered how to facilitate a workshop for students learning about designing in these types of conditions, Claude had the added firsthand experiences of working in the refugee camps and seeing the refugees struggle to make themselves homes within these difficult contexts, having been several times to the Zaatari camp in Jordan himself. Our common desire was to create a learning environment where we could inform students of the issues, support students collaborating together in the co-design approach, appropriating ideas, and ultimately having the students visioning possible futures through design learning (Poldma, 2009; Vaikla Poldma, 2013).

Thinking and doing as effecting changes through design action. This type of learning prepares students as professionals with skills for a practice of effecting change through design action. Fry (2009) proposes that the design profession be reframed as a re-directive practice that includes "...an exchange of knowledge and dialogue based on a common language of engagement..." (p. 55). Students can appropriate this type of approach by engaging in creating concepts that are both tangible and aesthetic while responding to very real needs. With these new skills, they can eventually enter the profession and engage in practices wherein dialogue is fundamental to solving problems, therein reframing how design practices are done.

Weigand (2000) also suggests that good design professors instinctively use these approaches by engaging students in reflective interaction. He cites Lee D. Mitgang's 
approach to learning when he discusses core elements of learning to design: "The core elements of architectural learning include learning to design within constraints, collaborative learning and refining knowledge through the reflective act of design - Design and wisdom can't be taught through lecture, only through interaction" (Weigand in Senge, 2000, pp. 179-180).

This type of reflective learning approach is a form of "thinking" and "doing." Students reflect about the issues ("thinking"), formulate ideas by designing ("doing"), and then reflect back on the concepts, judging their worth in the contexts of the issues raised ("thinking/doing"). This is both a way to learn as it is to develop the skills and values students will need in their future profession (Vaikla Poldma, 2003; Poldma, 2009). We grappled with how students in a theoretical design course in a Quebec university might apply their learning in problem-based contexts of engagement in actual, real-life scenario-building for the humanitarian crisis in Syria. How might the students apply theoretical and design skills they were learning to the real-world situation of refugee camps in neighboring Jordan?

To implement the co-design learning activity, Claude began with a detailed orientation for the students by presenting the issues with full visual images and details about the Zaatari camp. We then encouraged students to form small groups and then they began to brainstorm ideas together. As we toured the design studio, we encouraged them to discuss the issues. Claude spoke to the students frankly about the seriousness of the unfolding crisis and experiences of people living in refugee camps and provided firsthand accounts of the refugee experiences. At that time, interviews with refugees were not a possibility as the situation was too tenuous at the camps, so Claude provided visual images of the place, narrative from the refugees and firsthand accounts of how they lived and what their experiences were. While this was not ideal in that the students did not meet the refugees, at that time no refugees were in Canada and the logistics of such contact was considered to be very difficult, even impossible. Claude's information was very revealing, and he provided both on-the-ground images and aerial views of the camps, which assisted the students in terms of setting the contexts of the problem.

Students worked together from the onset, first familiarizing themselves with the problem and researching the subject, then creating concepts and details. Each group unveiled their particular concerns and generated preliminary ideas after a series of brainstorming sessions. Students were genuinely affected by the plight of the Syrians, and many were grappling with the crisis and the human toll it takes on families and children. They quickly tried to think of positive motifs and ways that 
they could bring innovative approaches to the ideas that they were generating. One group played with orange tones as a way to bring life and health, and many used everyday colorful found objects to incite design ideas.

It was evident that some students were having trouble dealing with the concept of refugees and how they actually lived. From their position of privilege they were seeing a part of human strife that they had not been exposed to. The social and political meaning of designing for a refugee crisis was made tangible in the very exercise of designing that they were engaged in. Every decision being made would have either a social, sustainable, or human impact on the refugee camp itself. This reflects on the ways that the camps become socioeconomic entities within their very framework, a mini "society" within an artificial urban environment (Dalal, 2014). Students were aware that they would help camp residents become empowered with the kinds of solutions they were proposing. For some this was exhilarating, and for others it was daunting.

Design process thinking and designing in context. Design thinking and design processes also include consideration of both technical and aesthetic aspects of a particular project. This means understanding how the environment is designed with elements of light and color, what are appropriate and/or necessary material choices and how furniture and accessories all fit within an interior space. These learning experiences are often theoretical in nature, in that students learn about light and color as theory first. As their professor, I try and make the concepts "real" by providing exercises that give them a sense of light, how to use color and why these elements are vital in their subsequent design concepts, and then how the theoretical ideas might be applied in projects. However, too often these learned qualities are limited to visual choices that are made by the students individually in controlled problems they explore later on in design studio. As such, the projects where they then apply ideas are within Western concepts of closed interior environments using conventional classroom strategies. The theory learnt is abstract in nature, whether it is about color and material choices, or conceiving the interior space using design elements such as line and form in the creation of a more abstracted interior space. Students are rarely exposed to users as real people with intimate personal experiences and how this is integrated into design concept development tangibly.

In the case of this project, theory had to be explored in the context of then proposing real solutions for a place and space that is very different from Western norms within a scenario that students were not familiar with. Accordingly, they needed to explore issues such as how Syrian homes worked, what cultural differences existed 
in Syrian lives, and how this was accentuated by the crisis of living in a refugee camp. Syrian homes are differently organized, and students needed to know the specific cultural nuances of living in tents as homes as well as living as a Syrian family in a tent. Students did extensive research on the camps, how Syrian families lived, and what needs they had both in their lives before they arrived at the camps and again as refugees. As some students in the class were Middle Eastern and of Syrian backgrounds, these students were invaluable for providing information back to those who were not as familiar culturally with Syrian ways of living. Students helped to provide the context needed for others, in terms of living styles, cultural needs, and understanding how Syrian families actually lived, before they ended up as refugees in the camps.

\section{A different type of learning journey-challenging assumptions, co-creating} using conversation and learning empathy. As teachers, we embarked together with students on a learning journey, and we wanted to create a learning experience that would engage students in the real problems of actual people, in part by challenging their Western assumptions of design of interior environments. Exposure to the world Syrian crisis and thinking about design in this context could challenge both the students' own experiences and knowledge as well as our own.

Students and professors are often in conversation and dialogue as a fundamental part of the student learning experience while designing. As Palmer (2003a) suggests, this includes exploring the "challenge of ideas, the exploration of shared practice... the mystery at the heart of educational exchange" (p. 1). Learning strategies include creating conversation and community, generating learning experiences that develop qualities of empathy, integrating theory with practice, and broadening worldviews. Additional goals include acquiring the qualities needed to practice effectively as a professional in the field, where dialogue with the user/client is essential.

Thus, the goals of the workshop culminate in creating a learning space for open conversation and reflection, while encouraging learning about uncomfortable issues to trigger responses and engagement about the phenomenon itself (Jalongo, 1991). In essence, this means co-designing as a collaborative process. As the teachers, we were convinced that putting the students into small working groups would facilitate their conversation with one another and also help them discover how to use research and design skills in the application of visioning solutions for severe problems unfamiliar to them. This requires, as Palmer (2003b) also notes, the development of critical thinking skills: "...to be in 'truth' you must be in the conversation....the 'conversation' of truth can and must be internal as well as external-internally, it is called 'critical thinking'" 
(paragraphs 11-12). Making the designing meaningful for the user/recipient means understanding the practical experiences, as these are actually lived by people in their situations, where their voices are heard and their concerns are considered as part of the design problem-solving. Providing opportunities for this type of learning was at the heart of the workshop we designed for students.

\section{Developing empathy with project-based learning and co-creative collaboration.}

We also envisioned working from the basis of an overarching principle and a question. The principle is: How to understand the phenomenon of the problem from a projectbased learning perspective. The question we asked: How to develop viable and innovative solutions in small teams using co-creation and collaboration strategies?

First, students needed to understand theories of design juxtaposed against the realities that drive professional practice, and consequently, problem-solving. Putting students into situations where client or user-simulated exchanges occur (with the professors) allows them to glean the ways that people have real, lived experiences. Teachers become facilitators of student learning by becoming the "clients" and for students, meeting clients in a simulated setting scenario is one way to develop empathy, as this approach makes the situation real for students. They understand how they can then develop the design concepts for people. As Savin-Baden and Major (2004) suggest, characteristics of project-based learning include: “...an integration of theory and practice,... a focus on processes ....and...concepts ...(such as) casedbased lectures .....where students meet with a client in some form of simulated format where free inquiry is allowed to take place..." (p. 5)

Students are confronted with the situation through the eyes of the user/client and then engage in discussion about the issues they witness. Using these strategies, students begin to understand how theory-informed concepts learned in the classroom can be understood, even applied, in practical situations (Vaikla Poldma, 2013).

Second, collaborative strategies both in the student groups and with the professors in each group, stimulated ideas and provided alternative perspectives on the issues students were exploring. We used the nature of the design studio and the smaller groups of two-three students per group to encourage these strategies. We would spend time with each group challenging ideas, discussing potential issues, pushing the ideas further, as students developed their ideas from rough sketches to working paper and cardboard or virtual models. They co-created together as they worked through ideas. Here in Figure 1 we see some of the early concepts drawn and in working form: 


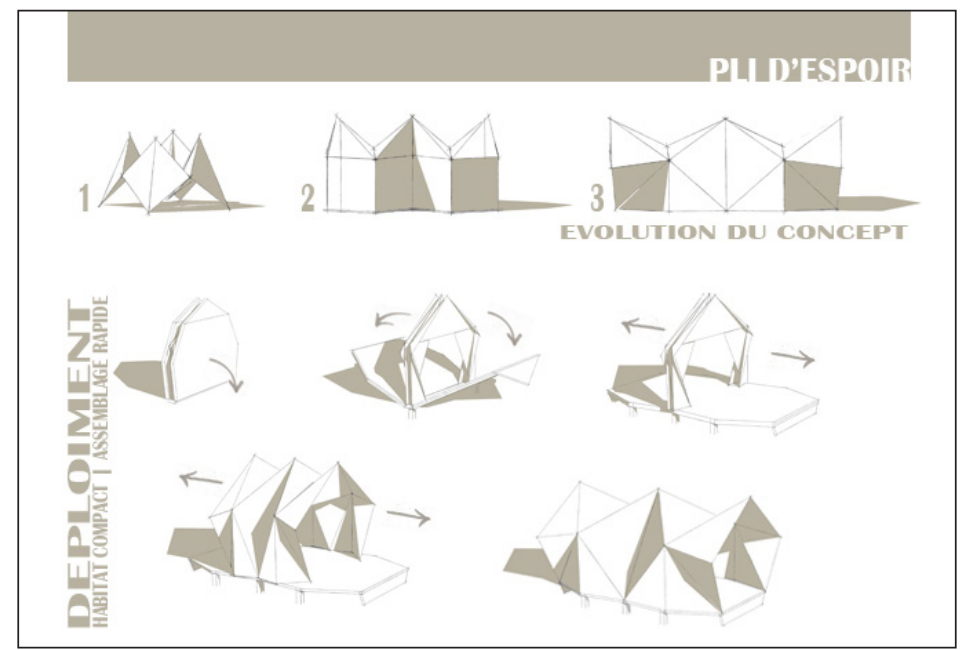

Fig. 1: Pli d'espoir (translation of image text: fold of hope, compact living-rapid assembly, and evolution of the concept)

We felt that these smaller groups would help students to quickly get to know one another, get to know the problem together, and converse among themselves more easily. In the small group, they could co-design using strategies of design thinking, while capitalizing on visual expression of their ideas using each other's strengths. Students were both encouraged and challenged when they proposed their ideas using active dialogue in the design studio classroom.

For example, as we were moving around the classroom, many students showed us ideas for children's play areas, conceptual paper models for proposed tent structures as in Figure 1, or simulated computer models of various lighting ideas. However, in one instance, we came across three students who were working together. They were all knitting plastic and we asked what they were up to, as they were not designing in the usual way that other students were doing. They decided that they had to use the one thing the refugees had plenty of, plastic garbage bags. Each one was knitting plastic shopping bags that they had cut into strips, into a scarf, a bag and other items. They had developed samples and were knitting objects, testing their ideas. They were also talking and joking as they were knitting and we were very taken by what they were doing as they were both creating their project and socializing while working on the samples. They then presented their concept of knitting through conversation and social activity to develop products, and how this might provide women with a means of socializing, of creating a business, and of achieving autonomy, a way to empower women in this dire situation. They were using the found 
materials and their skills to create useful and beautiful objects to sell in the camps to raise money for the family to be used for negotiation. Students had found that this type of project, capitalizing on women's skills, while creating objects, was a way to help their family and provide themselves with autonomy, thus capitalizing on the urbanization of the camps noted by Dalal (2014) in a proactive way. Money and goods were considered by these students as one of the rare commodities within the camps. Here we see their ideas in Figure 2:

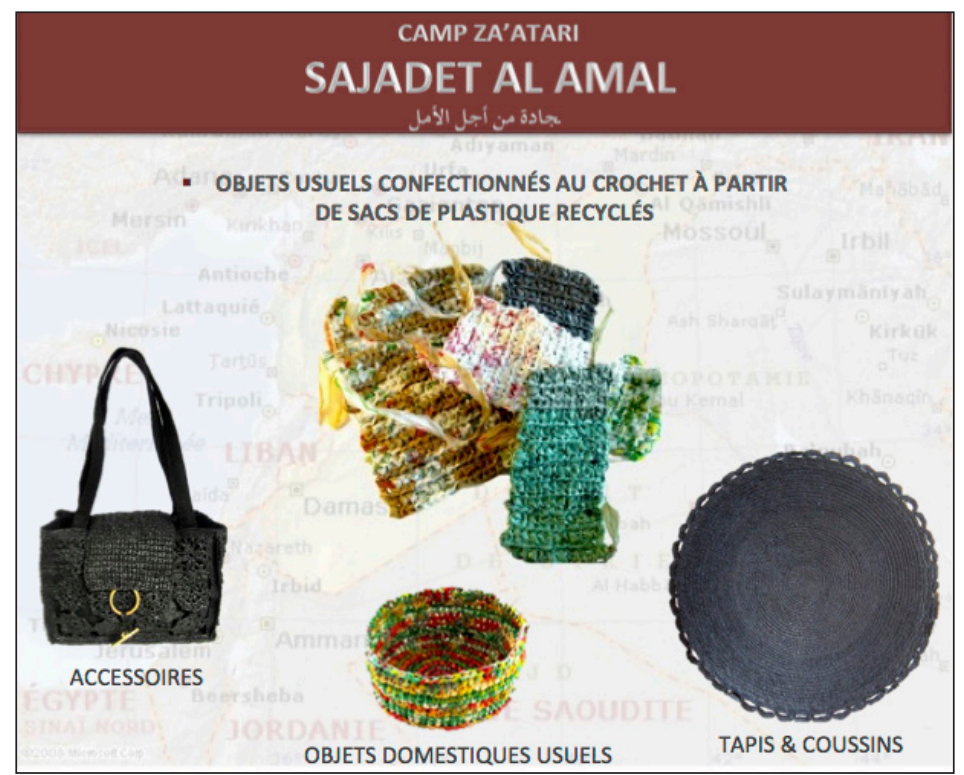

Fig. 2: Camp Za'atari Sajadet al amal (translation of image text: everyday objects created by crocheting recycled plastic bags; accessories; everyday domestic objects; carpets and cushions)

The visiting professor/client confirmed that he approved of both the ideas and their notion of creating a social space for creative objects, by creating usable goods for either sale or to barter for goods. We were both astounded and thrilled that students were thinking along these lines.

Using conversation to make meaning and design as a transformative tool. Both the project-based learning situation and the co-design strategies come together within the idea of conversation as a means to make meaning (Poldma, 2009; Vaikla Poldma, 2013). Design professionals make meaning in practice, with clients and of user desires and needs by engaging with them in conversation. This dialogue between designers and users allow clients/users to express their voices, thus allowing 
the designers to make meaning of what they want. They then can transfer this knowledge into tangible, visual concepts and solutions for the design problem at hand as they take a step back from the client and reflect on their needs. For students in the workshop, they needed to engage in tangible conversations with people who understand the Syrian refugee experience. Claude, as the professor with direct experience of the refugee camps, provided this conversation, being both Syrian and an eyewitness to the crisis unfolding in Syria, as did the fellow Syrian students who made the concepts real for their fellow students.

Many students were emotionally devastated about the children in these situations. We talked through their worries with them and they discussed what elements in design, such as color and light, would help to bring hope. These discussions became the catalysts of conversation and engagement with the "client," as students both grappled with these refugee living realities while trying to design solutions. This was done during both the first design concept development stage, to help students to flush out preliminary concepts, and also when they presented their final proposed concept/solutions to us.

\section{Integrating form, light and color with ethical and sustainable approaches to} workshop goals. Learning tools also included an emphasis on designing with form, color, and light, with an insistence on sustainable approaches that would work in the actual climate conditions and the realities of the camps in the desert. As the workshop occurred in a theory course about "Colour and Light in Interior Spaces," students were asked to consider light, color, material and form as ways of providing shadow and light from an intimate human perspective (Tanizaki, 1977/1980; Lidwell, Holden, \& Butler, 2003) while answering very serious and real issues of security and comfort in a foreign environment. Salient issues students discovered included concerns about self-hygiene, providing children with ways to change their crisis situation through play, considering social spaces, and looking into flexible and viable living solutions.

Furthermore, from an ethical perspective, students were asked to consider these design elements with a sustainable approach and using the principles of universal design (Lidwell et al., 2003), meaning that they were designing for families with all kinds of people in all kinds of situations. Sustainable solutions were obligatory, as the living conditions are so severe and limited that students had to be aware of these conditions and design realistically within the constraints of the Jordanian desert, the found materials available in the refugee camps, and using some of the things provided in the camps, by developing solutions using recycled materials. 
Students needed to glean what it means to understand design "for the other $90 \%$ " and in the context of designing for those with no means and using what is available in the situation at hand (Papanek, 1984; Design for the Other 90\%, 2015; Yacoub, 2013). Concepts of sustainable approaches take on different meanings in the context of a refugee campsite when compared to our view of sustainable issues in Canada.

Meanings of "home" in the context of a refugee camp. Finally, in trying to understand situational contexts, students needed to grapple with how the physical spaces of these contexts are completely different than their idea of home environments in their experiences in Quebec, Canada. Whether people live as families in a tent or in a brick-and-mortar house, these physical spaces carry with them social and psychological connotations and meanings. As Pheasant (1986) notes: "The physical characteristics of the spaces we inhabit also have psychological overtones" (p. 165). People live in homes and appropriate them, making meaning with objects and the environment that surrounds them, no matter how dire. They hold dear their personal and cultural representations through objects that they have available to them.

Issues of what is "home" and what is "shelter" were issues all students grappled with, to understand what home means to refugees from Syria. For example, in the crisis situation of the refugee camps, the nature of what objects attribute meanings for refugees becomes heightened by the very need to survive, and how what objects they have "...affect the development of the self" (Czikszentmihalyi \& Rochberg-Halton, 1981, pp. 50-51). The physical spaces where people lived in the camps are real places with objects and as such, are appropriated. Vital issues for students to understand about people and their lived experiences in these camps include issues of security, basic hygiene needs for women men and children, places to play, places to congregate and socialize, and places for what precious possessions people may have. Students were encouraged to consider how to help refugees use what they had available in ways that would help to lift them temporarily out of the dire situations that they faced.

The sequence of activities and project limitations. The workshop unfolded over two months with two distinct phases and within a condensed studio workshop format. First, in Phase 1, Claude as the visiting professor architect, prepared the students with research that they needed to do for the workshop when he returned in a couple of months. They were provided with a portrait of the refugees as users and their lived experiences, coupled with the physical realities of living in the Zaatari camp in Jordan. Students developed an understanding of the problem and situation, and devised early conceptual approaches. They then developed the final conceptual approach retained after discussion with the teachers. 
Then in Phase 2, Claude returned for two concept development classes and the final presentation (in three-hour classes spread over three weeks), during which students were to finalize their ideas, provide models (real or virtual) of proposed concepts for approval, and present the concepts in a concise format in class to a jury acting as a potential client/user. They presented the final concept for critique to a jury composed of architects and designers with experiences in the Jordan camps and in humanitarian design. The best solutions were then presented at a conference on humanitarian design in April 2014. Solutions were to be presented as final concepts in a limited format with concept, technical development and integration within the camp tangibly.

The challenge of the refugee as a real client. As noted earlier, Claude, as the visiting architect professor became the "user/client," provided students with many details about the living environment of the refugee camp, including videos and plans of the camp itself. With his personal accounts of life in the refugee camps, he could provide first-hand accounts of the camp experience and background that the students needed to situate the issues both realistically and appropriately.

As a learning activity, ideally, we would have liked to have students speak to a refugee engaged in the workshop as the real client. However, this was not possible at the time of the workshop. The refugees were in a dire situation and as such not directly accessible to students in North America. Claude gave the students the perspectives of the refugees as the next best thing. He became the one who gave the firsthand accounts of life in the camps from the perspectives of all the people living there, as the "client." He had just returned from a trip there and the issues were fresh as he presented them, as a "simulation refugee." For a baccalaureate workshop this was considered to be adequate, but not ideal. In an ideal situation or in a research project, firsthand accounts of lived experiences are the most accurate way to understand the ways that the refugees live.

Using precedents to understand sustainable and universal design issues as ethical issues. Students were asked to explore the issues at all the stages of a design concept and problem development, which normally includes looking at precedents in the form of different types of crisis solutions in design and architecture, sustainable considerations, and exploring universal design approaches (Papanek, 1984; McQuaid, 2003; Yacoub, 2013). Issues researched included a) How to reconcile post disaster issues alongside the realities and hardships of living in a refugee camp; b) How to see past the limitations of the living conditions of the camps; and c) How to apply design elements understood theoretically, such as color, light, material, 
and form, to the problems being studied; d) How to integrate these various issues from both ethical and sustainable views. These perspectives were studied from both practical, technical perspectives and ethical ones. Students were confronted with ethical dilemmas and understanding how their perspectives and ideas might be received in the refugee situation. This was very eye-opening for them.

Three examples of student concepts. Students produced over 35 concepts in two classes, with groups in first year and second year. The teams came up with innovative solutions ranging from personal hygiene devices, to growing sustainable gardens, to play structures and places for children, to community social spaces and various types of new concepts for living spaces.

Here are three examples of the concepts that students proposed:

Example 1 (first year students). Living in tents is precarious and makes children feel unsafe. In this concept, students provide a sustainable solution for repairing tents using LED technology, an efficient and sustainable way to provide light using light-emitting diodes (LEDs). Key words include concepts of magic, dream, and hope, with the concept of sleeping under the stars. The tent repair kit is both sustainable and creates a sense of safety for children and adults alike.

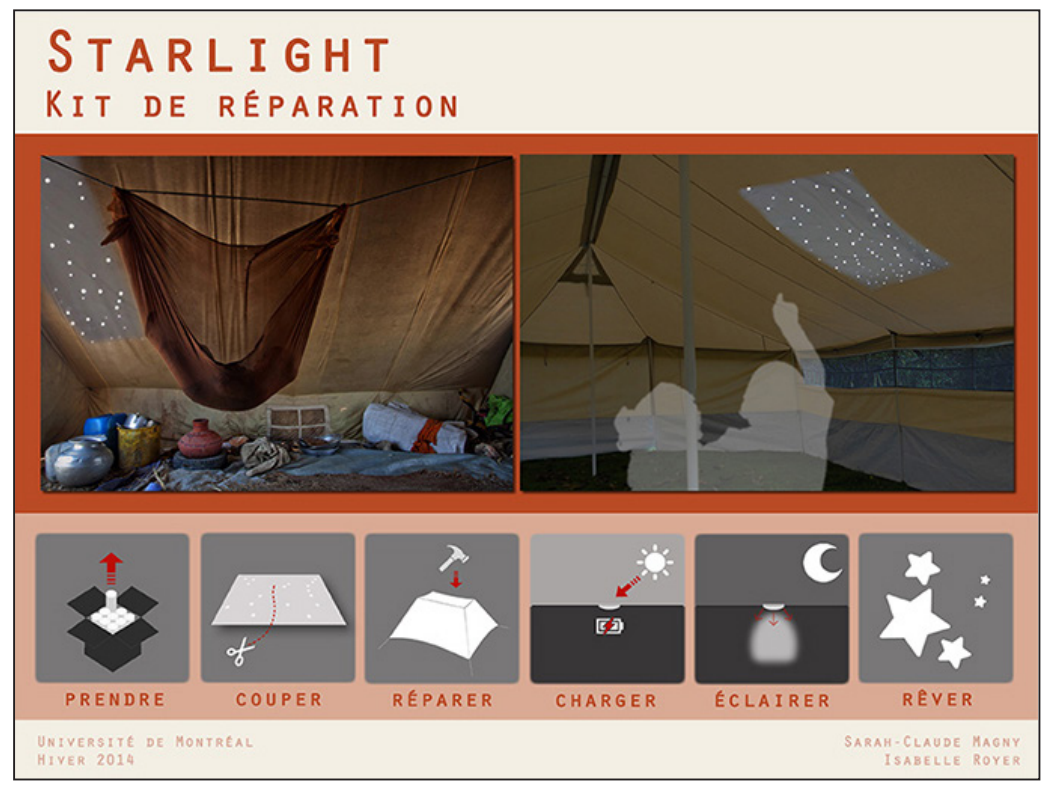

Fig. 3: Starlight kit de réparation (courtesy, first-year students) [Translation of image text: Starlight Repair Kit; remove from box, cut shape to fit, repair, charge the LED, light up, dream] 
Example 2 (second-year students). This student concept was specifically designed for the over 50,000 children aged 0-11 years in the camps. The students researched the needs of children, and how necessary it was to create a playful environment for them free from the ravages of war. Key words include ethics, action, crisis, humanitarian, learning, form, color, and light, with the inspiration of dynamism yet simplicity of play. In the end, and as seen in Figure 2, this concept allows for children to be children through color and a collapsible play structure.

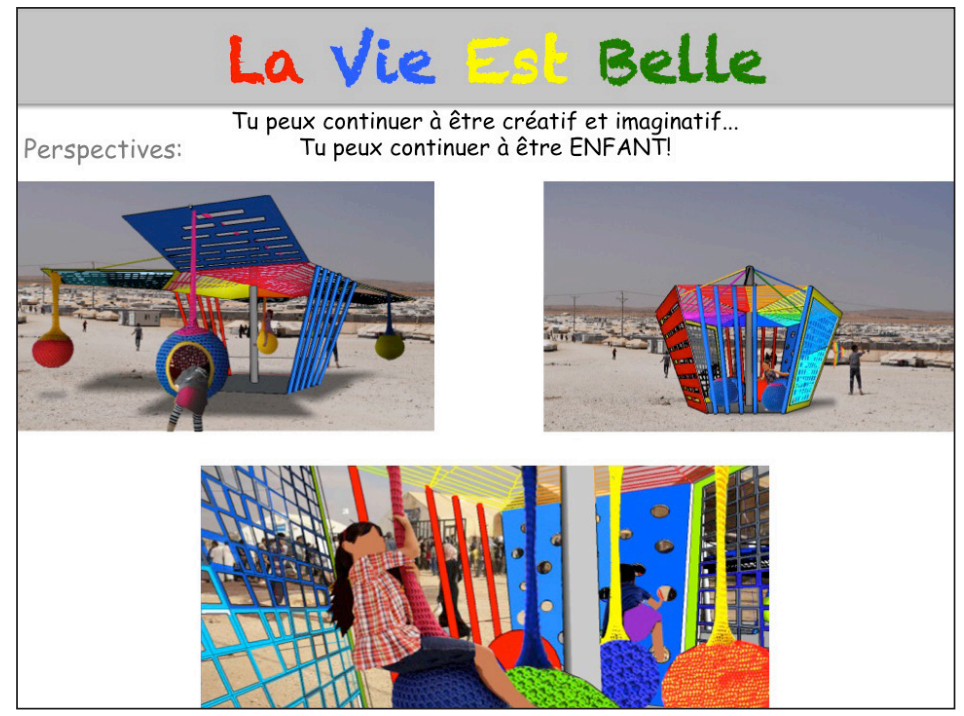

Fig. 4: La vie est belle (courtesy, second-year students) [Translation of image text: Life is beautiful. You can continue to be creative and imaginative... You can continue to be a CHILD!]

Example 3. In this sustainable solution, issues of protection from the elements and security drove the development of the concept. Student explored three main issues: sand winds, heat, and women's security at night. The resultant structure is both beautiful inside and practical outside. Made of bamboo and polypropylene, students made sure the design was recyclable and could easily incorporate a lit path for women at night, as seen in Figure 3. 


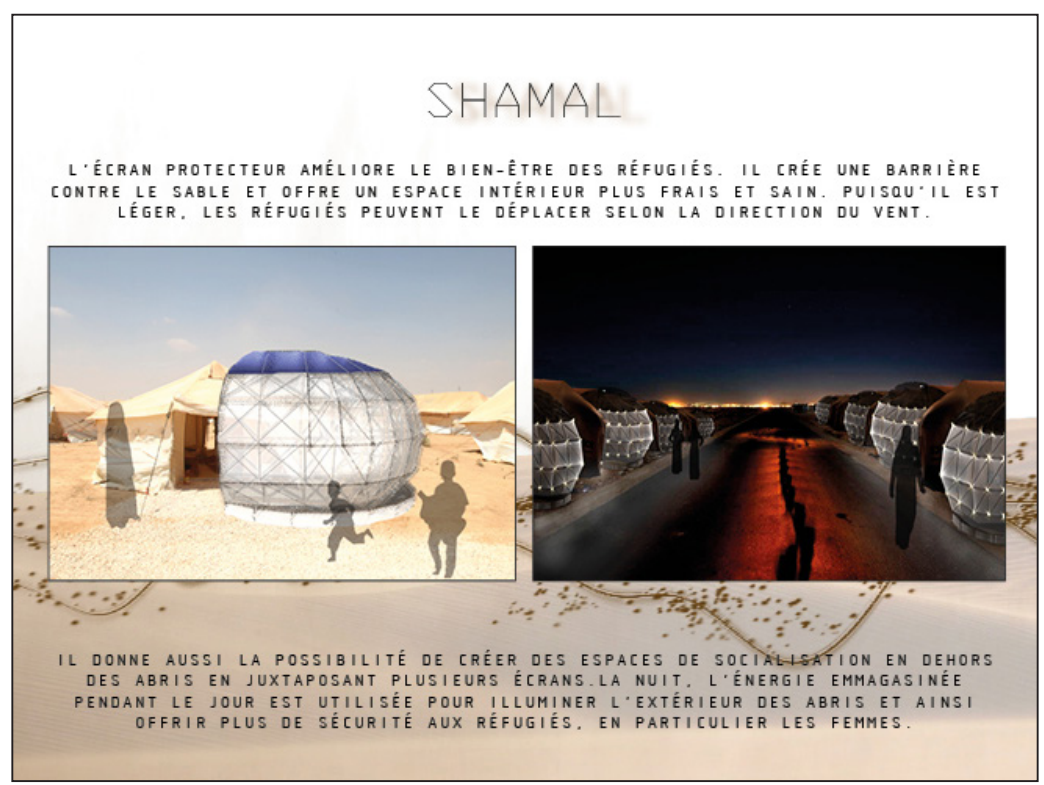

Fig. 5: Shamal (courtesy, first-year students) [Translation of image text: The protective screen improves the well-being of the refugees. It provides a barrier against sand and offers a fresher and healthier interior. Because of its lightness, the refugees can move it around with the wind. It also offers the possibility to create spaces outside the shelters by juxtaposing multiple screens together. This resultant energy offers increased security for the refugees. In particular for women.]

\section{Discussion}

While Claude and myself envisioned engaging students by providing them with new challenges, we did not anticipate how wholly and deeply students would appropriate the project, developing innovative, practical, and mostly sustainable solutions. The value that the project gave students in terms of their development of empathy and thoughtfulness emerging from the critical reflections that they did in their co-creation was witnessed in solutions that were playful yet appropriate, aesthetic yet sensitive, and in concert with the cultural and situational issues that the students identified.

Students were greatly affected by the issues they explored and certainly developed empathy, as the design solutions attest. The overall idea of allowing students to really understand and come to terms with the situation of the people in the camps was vital. Conversation and problem-situating were fundamental to understanding the experiences of the people in these dire situations. The conversations students engaged in were done hand in hand with various forms of visual exploration, such as 
direct product development, real material, and simulated physical and virtual models, all done collaboratively in the co-design learning experience. Research and context development happened alongside client context-situating and the development of thorough and thoughtful solutions. This was a major feat, given the extremely tight time frames of the project and much tighter than usually given for a project of this scope.

Reflective discussions accompanied the design development, such as how to personalize the spaces they were living within including the tents, the commissary, and the temporary pharmacy and schools. The plight of children particularly affected the students, and several of the solutions students developed with the desire to try and bring a sense of joy, of childhood, back to those who were not in that type of place, if even temporarily. Various proposals included the use of color, found materials, LED lighting technology, and other current technologies that were both appropriate for children and that could be implemented realistically within the camps. The issue of "shelter" and "home" for those who, essentially, are homeless, became salient issues explored, as well as providing flexible and viable solutions that could be transportable and have some aesthetic supported by feasible technological choices of materials.

\section{Linking Education With the Community}

Students informed the wider community of their learning experiences in two ways. First, they presented their concepts to architects and experts from humanitarian design perspectives. The jury members critiqued concepts and engaged students in discussions about the issues, confirming assumptions and refuting concepts as needed. These were animated discussions and the jury members appreciated the scope of the solutions proposed.

Second, the student ideas were presented to the wider community seeking solutions for the refugee crisis during the llaSouria-supported international conference held in Montreal in April 2014. This conference showcased examples of the student work, and empowered students to seek ways to bring their ideas further and into the real world by seeking out interested nonprofit organizations and showing them their concepts. This was an important step to link the wider humanitarian community worldwide to the issues that they explored locally in Montreal, Quebec, yet with potential impact in Jordan. Student concepts were presented as real, tangible concepts for consideration and subsequent discussions about potential solutions were proposed in terms of the realistic potential within the camps in the future. Given that the international community was essentially European and Middle 
Eastern, this forum offered an opportunity for the student workshop to be showcased in the international community, while also providing the community with ways to consider solutions that were innovative, possible, and visual, and created from a Quebec/Canada perspective. Ideas could be imagined for potential futures for camps in ways that had not been previously possible. Education came together with the humanitarian aid community in a tangible way, with serious interest shown to the locally created design concepts. Following the conference and workshop, some of the students pursued ideas with nonprofit organizations and currently, some of the students who were in the class are still exploring ways to get involved in the refugee crisis in Syria, through engagement with nonprofit organizations.

\section{Conclusion}

Learning that focuses on a humanitarian crisis brings potential ideas to the refugee community from the perspective of project-based and collaborative learning. For design learning to be relevant, students need exposure to design in the real world and to learn designing in context. Theory learned without situating the problem in the real situations of the person is useful, but generally remains aesthetic rather than grounded in problem-solving for the people for whom the design is conceived. The students in this workshop not only grasped issues unfamiliar to them, but they also used their design skills and applied their thinking in new and innovative ways. Students provided viable solutions situated in the issues at hand by engaging in a humanitarian design approach and that engaged the community in tangible ways.

Project-based learning, supported by giving real situations, provides ways for students to engage with professors, with one another, and with the communities they are serving. Making the project come alive with the client scenario allows for the facilitation of dialogue and the development of critical thinking skills. These are skills all students need, as they forge change in society. Students appropriated both the project and the issues and became proactive in developing further ideas about taking their design solutions to the refugee camps directly. Linking the community to education provides ways for students to become engaged and widen their worldview on their journey to becoming global citizens. 


\section{Acknowledgments}

I would like to thank the teacher, Claude Yacoub and the students in first and second year in the Winter 2014 Baccalauréat en design d'intérieur (BDI) program at the École de design, Université de Montréal, for making this workshop possible and supporting the research explored in this paper.

\section{Notes}

1. This workshop was also presented at the LearnX conference in Chicago in 2015.

2. Students consulted the following sites during the workshop:

- https://www.facebook.com/ila.souria/

- https://www.cooperhewitt.org/2011/04/22/cooper-hewitt-design-forthe-other-90/

- http://www.humanitariandesignbureu.com/accueil.html

- http://papanek.org/

- https://www.facebook.com/EARTH-water-ASSOCIATION-130567397034090/

- http://www.cooperativedesign.fr/

\section{References}

Csikszentmihalyi, M., \& Rochberg-Halton, E. (1981). The meaning of things: Domestic symbols and the self. Cambridge, UK: The Cambridge University Press.

Dalal, A. (2014). A socio-economic perspective on the urbanization of the Zaatari Camp in Jordan. Migration letters. Volume 12, Number 3, 263-278. Retrieved from http:// www.tplondon.com/journal/index.php/ml/ article/viewFile/513/406

Design for the Other 90\%. (2015). The Cooper Hewitt Museum of the Smithsonian Institute. Retrieved from http://www.designother90. org/
Edwards, A. (2016). Global forced displacement hits record high. UN Refugee Agency Retrieved from http://www.unhcr.org/news/ latest/2016/6/5763b65a4/global-forced-dis placement-hits-record-high.html

Fry, T. (2009). Design futuring: Sustainability, ethics and new practice. Sydney, Australia: University of New South Wales Press.

Jalongo, M.R. (1991). Creating learning communities: The role of the teacher in the 21st century. Bloomington, IN: National Education Service.

Lidwell, W., Holden, K., \& Butler, J. (2003). Universal principles of design. Gloucester, MA: Rockport Publishers, Inc. 
McQuaid, M. (2003). Shigeru Ban. London: Phaedon Press.

Palmer, P. (2003a). Good talk about good teaching: Improving teaching through conversation and community. Retrieved from http://www.mcli.dist.maricopa.edu/ events/afc99/articles.goodtalk.html

Palmer, P. (2003b). Good teaching: A matter of living the mystery. Retrieved from http:// www.couragerenewal.org/parker/writings/ good-teaching/

Papanek, V. (1984). Design for the real world. Human ecology and social change. New York: Van Nostrand Reinhold, Inc.

Pheasant, S. (1986). Bodyspace: Anthropometry, ergonomics and design. London: Taylor \& Francis Ltd.

Poldma, T. (2009). Taking up space: Exploring the design process. New York: Fairchild Publications.

Savin-Baden, M., \& Major, C.H. (2004). The foundations of problem-based learning. The Society for Research Into Higher Education. Maidenhead, Berkshire, England: Open University Press/ McGraw-Hill House.

Tanizaki, J. (1977/1980). In praise of shadows. Translation by T. J. Harper and E. G. Seidensticker, Sedgewick, ME: Leetes Island Books, Inc.

UN Refugee Agency. (2014). UNHCR report shows leap in asylum applications for industrialized countries. UNHCR News Stories. Retrieved from http://www.unhcr.org/532afe986.html
UN Refugee Agency. (2016). Figures at a glance. Retrieved from http://www.unhcr.org/fig ures-at-a-glance.html

UNICEF Syria Crisis Winter Humanitarian Situation Report. (2015). Retrieved from http://www.unicef.org/appeals/files/ UNICEF_Syria_Regional_Crisis_Human itarian_SitRep_-_Winter_Storm_2015__12Jan2015.pdf

Vaikla Poldma, T. (2003). An investigation of learning and teaching processes in an interior design class: An interpretive and contextual inquiry. Unpublished doctoral thesis. Montreal: McGill University, Author.

Vaikla Poldma, T. (2013). Meanings of designed spaces. New York: Fairchild Books, A Bloomsbury Imprint.

Weigand, J. (2000). Excerpt 4. The accidental vision. In Senge, P., Cambron-McCabe, N. Lucas, T., Smith, B., Dutton, J., and Kleiner, A. (Eds). Schools that learn. A fifth discipline fieldbook for educators, parents, and everyone who cares about education (pp. 176-180). New York: Doubleday/Currency.

Yacoub, C. (2013). Actes du colloque llasouria.01 Syrie: reconstructions matérielles et immatérielles ? Paris: lla Souria.

Yacoub, C. (2014). Actes du colloque llasouria.02 Syrie: Reconstructions immatérielles et matérielles? 3 et 4 avril, 2014, Montréal, QC. Paris: Ila Souria. 


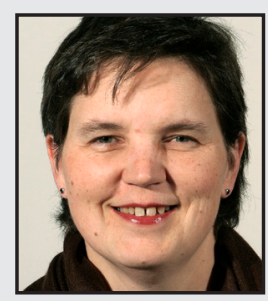

Tiiu Poldma is Full Professor at the School of Design, Faculty of Environmental Design, Université de Montréal, regular researcher at CRIR, the Centre for Interdisciplinary Research in Rehabilitation, and Director of the FoCOLUM Lighting Lab/Group for Research in Illumination and Design. She has extensive expertise in the design of indoor environments and human behavior in workplace, commercial, entertainment, hospitality, and residential environments. Educational interests include research methods, design processes, the development of current design thinking methods that challenge ideas about interior space, and project-based learning approaches that encourage creating adaptable, temporal, and flexible spaces using color, light, and design elements from universal perspectives. 